\title{
La Declaración Conjunta sobre la Doctrina de la Justificación veinte años después
}

\author{
Pablo Blanco-Sarto \\ Facultad de Teología \\ UNIVERSIDAD DE NAVARRA \\ pblanco@unav.es
}

Resumen: La adhesión a la Declaración Conjunta sobre la Doctrina de la Justificación por parte de luteranos, metodistas, reformados, anglicanos y católicos indica que esta constituye una referencia y un punto de partida para proseguir el diálogo ecuménico. El acuerdo teológico está basado en el "consenso diferenciado" de la propia perspectiva a la otra, sin renegar de los propios principios. Los viejos temas debatidos de las buenas obras, la concupiscencia o el simul iustus et peccator requieren a su vez una profundización y una reinterpretación, guiada por la "hermenéutica de la confianza". Necesitamos ahora una Declaración Conjunta sobre Eucaristía, ministerio y eclesiología, sin olvidar las cuestiones morales (bioética, medio ambiente, doctrina social) y la discusión del principio protestante de la sola Scriptura.

Palabras clave: protestantismo, gracia, libertad, concupiscencia, sola Scriptura

Abstract: The Joint Declaration on the Doctrine of Justification by Lutherans, Methodists, Reformed, Anglicans and Catholics indicates that this constitutes a reference and an starting point to continue the Ecumenical Dialogue. The theological agreement is based on the "Differentiated Consensus" of one's perspective to the other, without denying one's own principles. The old debated topics of good works, concupiscence or Simul Iustus et Peccator require in turn a deepening and a reinterpretation, guided by the "Hermeneutics of Trust". We now need a Joint Declaration on Eucharist, ministry and ecclesiology, without forgetting the moral issues (bioethics, environment, social doctrine) and the discussion of the protestant principle of Sola Scriptura.

Keywords: protestantism, grace, freedom, concupiscence, sola Scriptura 


\section{INTRODUCCIÓN}

El acuerdo fue firmado en 1999 en Augsburgo, en la iglesia luterana de Santa Ana, por la Iglesia católica y la Federación luterana mundial. Fue después suscrito en 2006 por el Consejo metodista mundial. Más adelante, el 5 de julio de 2017, con motivo de la conmemoración de los 500 ańos del inicio de la Reforma, fue a su vez firmado por la Alianza reformada mundial (compuesta fundamentalmente por zwinglianos, calvinistas y presbiterianos) y el 31 de octubre -el Día de la Reforma- por la Comunión anglicana, tal como había aprobado previamente el Anglican Consultative Council celebrado en Lusaka (Zambia) del 8 al 16 de abril del año anterior. Así, aquel 31 de octubre de 1999 (aniversario del día en que supuestamente Lutero colgó las 95 tesis) fue la fecha escogida para firmar la Declaración Conjunta sobre la Doctrina de la Justificación (DCDJ) inicialmente entre católicos y luteranos, y después reconocida por un amplio porcentaje de protestantes. A pesar de las polémicas suscitadas por algunos teólogos en un primer momento, hoy día es un texto pacíficamente aceptado que constituye una premisa, una plataforma común para un ulterior diálogo teológico en torno a otras cuestiones cruciales, como la interpretación de la Escritura o las distintas concepciones sobre la eucaristía, el ministerio o la eclesiología. En estas líneas veremos los precedentes del documento de 1999, el contenido, los desarrollos y las perspectivas de futuro ${ }^{1}$.

\section{ITINERARIO REDACCIONAL}

En octubre de 1513 Martín Lutero había iniciado las clases de Sagrada Escritura en la Universidad de Wittemberg, y durante los cuatro años siguientes recorrió los salmos y las epístolas paulinas a los romanos, a los gálatas y a

1 A. Maffeis, "La dottrina della giustificazione da K. Barth a oggi", en G. Ancona (ed.), La giusticazione (Messaggero, Padova 1997) 113-194. Sobre los mencionados temas de diálogo ecuménico, puede verse: P. Blanco SARTO, Ministri Ecclesiae. Eucaristía, ministerio y eclesiología en el diálogo católico luterano (Bibliotheca Oecumenica Salmanticensis, Salamanca 2017. Prólogo de monseñor Adolfo González Montes). Un primer acercamiento a la cuestión aquí abordada tuvo lugar en los Cursos de La Granda (Asturias) "La Reforma protestante. 500 años después", con la ponencia "Sólo Cristo y su gracia: La Declaración conjunta de 1999", durante los días 28-30 de agosto de 2017. Mi agradecimiento va dirigido a monseñor Juan Antonio Martínez Camino, obispo auxiliar de la archidiócesis de Madrid; a Olegario González de Cardedal, de la Pontificia Universidad de Salamanca y Ángel Cordovilla, de la Pontificia Universidad de Comillas en Madrid, y a todos los demás ponentes de este encuentro, por las sugerencias y críticas aportadas. 
los hebreos. Llegó a conocerlas casi de memoria. Pasados estos cuatro años, se había realizado en él una profunda transformación. Ahora bien, nos preguntamos todavía ahora, ¿cómo tuvo lugar este cambio de pensamiento? Como es bien sabido, este aparece claramente en el comentario a la Epistola a los romanos, que resume a su vez sus lecciones entre 1505 y 1518. En estas fechas ya había tenido lugar el cambio interior de Lutero en lo que él llama la "experiencia de la torre" (Turmerlebnis), una luz especial que, según él, recibió de Dios y que le solucionaba todas sus angustias y dificultades. En ella influyeron tanto su rechazo del voluntarismo ockhamista de Gabriel Biel (1420-1495), como su experiencia personal sobre la necesidad de la gracia para la vida cristiana. Sin embargo, no hemos de olvidar que los comentarios luteranos a los textos paulinos permiten, salvada su unilateralidad, una interpretación ortodoxa. De hecho, la mayoría de las 95 tesis permiten una lectura netamente católica. De esta forma, la actitud del hombre ante el don de la fe es la de quien se abre a la gracia, para dejar que solo ella actúe. Por eso la fe es un regalo de Dios que obra la justificación del cristiano y que exige un total abandono en el poder justificador de Dios. La justificación acontece, por tanto, sin las obras de la Ley: tan solo por la fe en Jesucristo ${ }^{2}$.

Por eso escribe Joseph Lortz (1887-1975): "Lutero fue un hombre extraordinariamente religioso, un verdadero homo religiosus". Sin embargo, sostiene también el estudioso alemán que estaba también un tanto aislado en este afán: sentía una absoluta necesidad de asegurar su propia salvación, frente a la teología ockhamista que defendía un voluntarismo arbitrario por parte de Dios 3 . "El tema «justificación» -escribe Gómez Heras- condensa la quintaesencia de la concepción protestante de Dios y del hombre"4. Es el articulus stantis et cadentis Ecclesiae y el "rector y juez de todas las demás doctrinas cristianas", el principio interpretativo de todas las verdades cristianas. Sin embargo, han pasado ya cinco siglos que nos permiten observar con más distancia y objetividad los aciertos y carencias de esta crítica doctrinal. El tiempo ha jugado a favor de historiadores y teólogos, y ahora es posible un

2 Sobre este tema, puede verse por ejemplo P. Blanco - J. Ferrer, Lutero, 500 años después. Breve historia y teología del protestantismo (Rialp, Madrid 2017²) 19-24. Para conocer el contexto histórico y teológico, resulta también interesante el trabajo de M. Svensson, "La idea de reforma en los reformadores del siglo xvi”, Scripta Theologica 50 (2018) 321-345.

3 J. LoRTz, Historia de la Iglesia en la perspectiva de la historia del pensamiento, II: Edad moderna y contemporánea (Ediciones Cristiandad, Madrid 1965) 146.

4 J.M.G. Gómez-Heras, Teología protestante. Sistema e historia (BAC, Madrid 1972) 48. 
diálogo mucho más sereno, quizá sin los apasionamientos y las controversias de los primeros tiempos. Permite leer tanto los textos luteranos como el decreto tridentino sobre la justificación con más tranquilidad y clarividencia. Recapitulemos pues ahora y veamos la situación del diálogo teológico interconfesional. Las conversaciones con los luteranos tras el Concilio Vaticano II tienen una larga historia, pues ya en 1967 fue creada en Zúrich la Comisión mixta entre la Iglesia católica y la Federación luterana mundial. Según indica Jutta Burggraf (1952-2010), "puede decirse que se ha avanzado más en el periodo posconciliar del Vaticano II, que en los 450 años precedentes". El trabajo teológico ha sido largo, pero ha obtenido sus frutos y, por tanto, vendrá bien recordar las fases de elaboración del conocido documento interconfesionals:

a) En la primera fase (1967-1972) encontramos el Documento de Malta significativamente titulado El Evangelio y la Iglesia (1972), en el que se reconoce la justificación como el núcleo teológico sobre el que se debe dialogar. Era un primer punto de partida, que dará sus frutos con el paso del tiempo. Allí se apreciaba ya un "amplio acuerdo" entre los teólogos de ambas confesiones sobre la vexata quaestio de la justificación del impío.

5 J. Burggraf, "La declaración conjunta católico-luterana de 1999 acerca de la justificación”, en Anuario de historia de la Iglesia 9 (2000) 511. Sobre la situación previa a este documento, puede verse: A. González Montes, Justificados en Jesucristo. La Justificación en el diálogo ecuménico actual (UPSA, Salamanca 1989). Además, entre los muchos títulos, podemos señalar: E. LAPIERRE, "Joint declaration on the doctrine of justification", en Ecumenism 141/3 (2001) 3-36; A. Meis W., "El problema de la salvación y sus mediaciones, en el contexto de la Declaración Conjunta católico-luterana sobre la doctrina de la justificación”, en Teología y Vida 42/1-2 (2001) 89-121; A.D. FalConer, "The joint declaration: A faith and order perspective: The joint Declaration of the Doctrine of Justification soteriological and ecclesiological implications", en Journal of ecumenical studies 38/1 ( 2001) 5-16; L. TuRCESCU, "Soteriological issues in the 1999 lutheran-catholic joint declaration on justification: An orthodox perspective", en Journal of ecumenical studies 38 (2001) 64-72; W.G. RusCH - G.A LiNDBECK, Justification and the future of the ecumenical movement: the Joint declaration on the doctrine of justification (Liturgical Press, Collegeville 2003); I. TAYLOR, "Without justification?: The Catholic-Lutheran Joint Declaration and its Protestant critics", en The Way 43/3 (2004) 106-118; J. A. Radano, Lutheran and Catholic reconciliation on justification. A chronology of the Holy See's contributions, 1961-1999, to a new relationship between Lutherans and Catholics and to steps leading to the Joint Declaration on the Doctrine of Justification (Eerdmans, Grand Rapids 2009); AA.VV., Zehn Jahre Gemeinsame Erklärung zur Rechtfertigungslehre - 10 years Joint Declaration on the Doctrine of Justification: documentation of the jubilee year celebration in Augsburg 2009 (Bonifatius-Lembeck, PaderbornFrankfurt am Main 2011); AA. VV., The biblical foundations of the doctrine of justification: an ecumenical follow-up to the Joint Declaration on the Doctrine of justification (Paulist Press, New York 2012); A. Lane, “Justification by faith 1517-2017: What has changed?", en Tyndale Bulle$\operatorname{tin} 69 / 2(2018)$ 283-303. 
Como indica Enrique Benavent, la doctrina de la justificación no es solo el articulus stantis et cadentis Ecclesiae, sino que constituye el criterio inicial para acometer la reforma de la Iglesia y una llamada permanente para que no olvide su propia misión: la justificación y santificación de hombres y mujeres por la gracia de Cristo ${ }^{6}$.

b) En una segunda fase (1972-1985) aparecen distintos documentos sobre cuestiones particulares derivadas de este gran principio hermenéutico que atañe a toda la fe, y relacionadas con las mencionadas cuestiones de la eucaristía, el ministerio y la eclesiología: La Cena del Señor (1978), Caminos hacia la comunión (1980), El ministerio espiritual en la Iglesia (1981) y Ante la unidad (1984). Tras la visita de Juan Pablo II a Alemania, había sido creada una comisión ecuménica mixta para fomentar el diálogo teológico en esas tierras. También figuran entre estos documentos del diálogo bilateral un texto sobre el reformador (Martín Lutero, testigo de Jesucristo, de 1983), así como algunos documentos elaborados por grupos nacionales, como por ejemplo uno sobre la justificación redactado en Estados Unidos (1985), así como otro de gran interés publicado en Alemania sobre la situación actual de las mutuas condenas pronunciadas en los años inmediatamente posteriores al inicio de la Reforma (1986) ${ }^{7}$.

c) La tercera fase (1986-1993) culminó con el texto titulado Iglesia y justificación (1993), en el que queda constatado que no existe un acuerdo sobre el concepto de sacramentalidad en la Iglesia, es decir, como receptora y mediadora de la salvación. Nos adentramos así en cuestiones eclesiológicas, en las que la Esposa de Cristo no solo es entendida como serva Verbi, sino también como "sacramento universal de salvación" (cf. LG 1,2; 48,2; 59,1; GS 45,1; AG 1,1; 5,1). Iglesia y justificación son efectivamente dos realidades igualmente originarias en el misterio cristiano. Sin embargo, en las mencionadas cuestiones eclesiológicas nos encontramos todavía en posiciones lejanas, sobre todo respecto a cuestiones referidas a la autoridad y el ministerio en la Iglesia. Queda por otra parte clara la prioridad del Evangelio sobre la Iglesia, la cual presenta la proclamación de la Palabra como una de sus más importantes misiones.

d) En la cuarta fase (1993-1996) es elaborado el proyecto de acuerdo

6 Cf. E. Benavent Vidal, "Actualidad de la doctrina de la justificación", en Anales valentinos 23 (1997/45) 8 .

7 H. Meyer - H. Schütte (Hgrs.), Confessio Augustana. Bekenntnis des einen Glaubens. Gemeinsame Untersuchung lutherischer und katholischer Theologen (Lembeck, Paderborn - Frankfurt a.M. 1980). 
sobre la doctrina de la justificación, en el que se constata que existe una concordancia general, pero que subsiste todavía una cierta diferencia de acentos: la justificación viene solamente por la gracia, pero su recepción permite las buenas obras, tal como expuso el Decreto sobre la justificación de Trento al analizar las relaciones entre gracia y libertad (cf. DS 1521-1526). Nos hallamos pues ante una cuestión de matices y subrayados, que -si bien no puede ser obviada- no debe impedir comprender la posición contraria, siempre y cuando no se niegue ninguna de las dos instancias imprescindibles y complementarias: gracia y libertad.

e) La quinta fase (1996-1999) va a suponer un intenso sprint final. En 1997 aparecen los Würzburger Text I y II, el cual fue aprobado por las autoridades luteranas al año siguiente. En enero de ese año 160 teólogos luteranos amonestaron a los líderes de sus propias iglesias para que se distanciaran del texto ${ }^{8}$. Para la correcta comprensión del texto en toda su amplitud y profundidad, la respuesta católica apareció el 25 de junio de 1998 y abrió la vía a ulteriores consensos. Así, como perspectivas pendientes, quedaban en el aire preguntas como la dimensión visible de la Iglesia, el ministerio, la confesión y los sacramentos. Como afirmaba Burggraf, suponía "una meta intermedia que constituye, a su vez, una base segura para continuar en la investigación teológica ecuménica y para afrontar las dificultades que todavía existen, con una esperanza más fundada de que puedan ser resueltas en el futuro" 9 .

Tal vez el caso más conocido es el de E. JüNGEL, El Evangelio de la justificación del impio (Sígueme, Salamanca 2004). Allí declara su "decepción", "porque en ella, o bien se habían oscurecido, o bien se habían abandonado por completo ideas decisivas de la Reforma” (10). Según el teólogo luterano, los términos en que se expresa la Declaración son equiparables a los del decreto tridentino de la justificación de 1547. Según Jüngel, "nos hallaríamos ante un texto que sería en el fondo hiperromano" (15). Allí recoge también un interesante itinerario de los comentarios y polémicas periodísticas del texto, que resultan interesantes para conocer la intrahistoria del documento. Allí concluye que "la exigencia de que el Evangelio de la justificación del impío no solo hay que traducirla al lenguaje de nuestros tiempos, sino que además hay que darle vigencia en la praxis eclesial por ser la verdad que dirige y encamina esa praxis" (16).

9 Cf. J. Burggraf, "La declaración conjunta católico-luterana de 1999 acerca de la justificación”, 517518. Como anécdota podemos añadir que este documento fue "desbloqueado" en el mes de noviembre de 1998 por el entonces cardenal Joseph Ratzinger (n. 1927), el obispo luterano Johannes Hanselmann (1927-1999) y los teólogos Joachim Track (n. 1940) y Heinz Schütte (1923-2007) en la casa del antiguo profesor de teología en Pentling, hasta llegar a una fórmula aceptable para ambas confesiones (cf. Amt der Vereinigten Evangelisch-Lutherischen Kirche Deutschlands (VELKD) - Johann-Adam-Möhler-Institut für ÖKumenik, im Auftrag des Sekretariats der Deutschen BisCHOFSKONFERENZ (DBK) - KOMMISSION FÜr ÖKUMENISCHE BEZIEHUNGEN DER EVANGELISCHmethodistischen Kirche (EмK) in Deutschland, Unter dem Horizont der Gnade Ökumenische Arbeitshilfe zum 10. Jahrestag der "Gemeinsamen Erklärung zur Rechtfertigungslehre"(DZA Druckerei zu Altenburg, Hannover - Paderborn - Frankfurt am Main 2009) 8-9. 
Finalmente, el 31 de octubre de 1999, católicos y luteranos firmaron un documento para poner punto final a un enfrentamiento doctrinal que se había iniciado 482 años antes, cuando Lutero envió sus famosas 95 tesis al arzobispo de Magdeburgo, Alberto de Brandenburgo. La doctrina de la justificación -no lo olvidemos- constituye el tema teológico fundamental que está en la raíz de aquel enfrentamiento del reformador alemán con la autoridad de la Iglesia romana. Este acuerdo fue firmado en efecto por el cardenal Edward Cassidy (n. 1924), entonces presidente del Pontificio consejo para la promoción de la unidad de los cristianos, y Christian Krause (n. 1940), presidente de la Federación luterana mundial. Se comprende que, para el acto de la firma, fuera elegido una ciudad -Augsburgo- y una fecha 31 de octubre- que tienen tanto significado en la historia de la Reforma protestante: allí fue rubricada en 1530 la célebre Confesión inspirada por Philip Melanchthon (1497-1560), que siempre ha sido entendida en el seno de la teología reformada como un acercamiento a las posiciones católicas. Además, la Confessio augustana, reconocida también por los componentes de la Liga de Esmalcalda, fue elevada en la Paz de Augsburgo, en 1555, como base de derecho público por parte de las iglesias luteranas ${ }^{10}$.

\section{Contenido de la DCDJ}

Nos encontramos así, por vez primera en el diálogo luterano-católico, con un documento aprobado inicialmente por la autoridad de la Iglesia católica y la de la Federación luterana mundial, preparado a su vez por la citada Comisión mixta oficial luterano-católica. Esta Declaración conjunta presenta una importancia difícil de exagerar, pues era la primera vez que, desde que Lutero rompió con la Iglesia romana hace ya cinco siglos, se llegaba oficialmente a un acuerdo en materia doctrinal sobre la cuestión central del protestantismo, entre la Iglesia católica y las distintas comunidades protestantes. Constituía tan solo un comienzo que puede presagiar un buen fin: un posible common ground para ambas confesiones, con un aparato bíblico atento y cuidadoso (cf. nn. 8-12). La DCDJ no pretendía añadir nada al trabajo realizado en los ańos anteriores, sino presentar una síntesis para ser analizada por las autoridades luteranas y católicas. Partía de una "hermenéutica de la confianza" -en expresión de Maffeis- que presentaba la propia fe para ser aprobada por la otra confesión cristiana. Los desarrollos

10 Cf. J. Burggraf, "La declaración conjunta católico-luterana de 1999 acerca de la justificación", 511, n. 1 . 
exegéticos y teológicos permiten formular ahora de modo equilibrado y no polémico la doctrina de la justificación ${ }^{11}$.

Como afirma Villar, "el objetivo de la Declaración conjunta es presentar hoy la doctrina de la justificación, a la luz de la profundización en las últimas décadas", para llegar así a "verdades fundamentales" (Grundwahrheiten) sin incurrir de nuevo en recíprocas condenas ${ }^{12}$. Sin embargo, ahora la disputa sobre el modo de justificación había sido superada al buscar el núcleo de una verdad compartida por católicos y luteranos:

Confesamos juntos -afirma la Declaración- que no en razón a nuestros méritos, sino solo por medio de la gracia y en la fe en la obra salvadora de Cristo, somos aceptados por Dios y recibimos el Espíritu Santo, el cual renueva nuestros corazones, nos capacita y nos llama a cumplir buenas obras [guten Werken] (n. 15) ${ }^{13}$.

"Juntos confesamos" significa la afirmación de una fe común, dejando espacio para una interpretación complementaria y no contradictoria con

11 A. MAfFeis, "Dichiarazione congiunta sulla dottrina della giustificazione", en ID. (ed.), Dossier sulla giustificazione. La dichiarazione congiunta cattolico-lutterana, commento e dibattito teologico (Queriniana, Brescia 2000) 23-56. Otras ilustrativas exposiciones y comentarios de este documento se encuentran en W. KASPER, "La Dichiarazione congiunta sulla dottrina della giustificazione. Un motivo di speranza", en Euntes Docete 53/1 (2000) 7-14; A.N.I. AbdelmalK, "La dottrina della giustificazione: uno sguardo ecuménico", en Theologica Xavierana 180 (2015) 409-445; M. Scandroglio, "La comunione possibile. La 'Dichiarazione congiunta sulla dottrina della giustificazione' come tappa fondamentale nel dialogo fra le Chiese”, en La Scuola Cattolica 145 (2017) 281-308.

12 J.R. VilLaR, "La declaración común luterano-católica sobre la doctrina de la justificación", en Scripta Theologica 32 (2000/1) 108. En efecto, la doctrina de la justificación (es decir, de cómo el hombre pecador puede salvarse) fue la cuestión central en la discusión de Lutero con la autoridad de la Iglesia, de modo que las diversas interpretaciones fueron objeto de condenas recíprocas, tanto por parte del Concilio de Trento como de los propios luteranos hacia los católicos. Según los protestantes, Dios declara justo al pecador aunque no lo sea de verdad, siguiendo la doctrina del simul iustus et peccator, pues no es posible una transformación interior del hombre dañado radicalmente por el pecado. Lutero, perseguido por el temor de la eterna condena, necesitaba creer que Dios lo consideraba justo, aunque fuera pecador. Por el contrario, según Trento, la gracia no solo cubre los pecados, sino que transforma realmente al hombre de pecador en justo, al cooperar la voluntad humana que acepta la gracia. Lo que permanece no es el pecado sino la concupiscencia o fomes peccati, que es una tendencia o inclinación al pecado.

13 A este texto se une la "Risposta della Chiesa cattolica alla dichiarazione congiunta fra la Chiesa cattolica e la Federazione luterana mondiale circa la dottrina della giustificazione", en A. MaffeIs (ed.), Dossier sulla giustificazione, 67-74; en adelante lo citaremos brevemente como "anexo". 
la otra, que constituye a su vez una explicación legítima de la misma fe. La justificación tiene lugar, por tanto, por medio de la gracia en la fe, pero "dicha fe es activa en el amor y, entonces, el cristiano no puede ni debe quedarse sin obras" (n. 25). El acuerdo no se propone hacer un juicio histórico sobre los problemas de la fe tal como se dieron ayer, sino buscar la común confesión hoy. En la perspectiva católica, lo que estos documentos dicen es que a los luteranos que ahora confiesan la doctrina de la justificación, tal y como se presentan en estos textos no les alcanzan las condenas del Trento, pues no profesan -por decirlo con la palabra clásica- la herejía condenada. El acuerdo de Augsburgo viene a decirnos que confiesan una doctrina en la que hay acuerdo entre católicos y luteranos, y es -en este sentido- "doctrina católica”. En el documento se reconoce claramente por parte luterana que la donación de la gracia justificante puede ser rechazada por el pecador, lo cual es una forma clara, al menos implícita, de decir que la posición de hombre ante Dios no es "meramente pasiva" (cf. n. 21) ${ }^{14}$.

Con todo, este acuerdo sobre el tema de la justificación, raíz y artículo fundamental de las diferencias luteranas, lleva a los protestantes a situar este tema en el eje de la "jerarquía de verdades" que condiciona el modo de concebir la Iglesia, los sacramentos y toda la doctrina de fe, y puede llevar a revisar en consecuencia sus antiguas posiciones. Hay matices y explicaciones, como por ejemplo del tradicional término católico cooperatio gratiae, entendido como "un fruto de la gracia y no una acción que dimana de una innata capacidad humana [kein Tun des Menschen aus eigenen Kräften]” (n. 20). Además, el mere passive luterano es entendido aquí como "plena participación personal e $\mathrm{n}$ la fe [sein volles personales Beteiligtsein im Glauben]" (n. 21). Como consecuencia, la "acción de la gracia de Dios no excluye la acción humana", concluye el anexo del texto que contiene los comentarios a la declaración publicados por la Congregación para la doctrina de la fe (n. 2, C). La justificación solo puede venir durch Glauben und aus Gnade, pero a su vez ha de tener en cuenta que "la fe que obra por la caridad" (Ga 5,6): por la fe Dios confiere el don de una nueva vida en Cristo; esta nos obtiene

14 Cf. J.R. VILLAR, "La declaración común luterano-católica sobre la doctrina de la justificación", 107 ss. El entonces cardenal Ratzinger afirmó entonces que con el acuerdo "se ha alcanzado un consenso sobre verdades fundamentales para la doctrina de la justificación, pero quedando otros problemas sin resolver". La cuestión se vuelve más real -añadía- si tomamos en consideración la presencia de la Iglesia en el proceso de justificación y la necesidad del sacramento de la penitencia: "Aquí aparecen las verdaderas divergencias", concluía. 
el perdón de los pecados y la consiguiente santificación (cf. Rm 5,1 y 1Jn 3,1), "una vida nueva en Cristo" (n. 22).

Somos verdadera e internamente renovados por la acción del Espíritu y siempre permanecemos dependiendo de su acción en nosotros: "Si alguien es en Cristo, ese ya es nueva criatura, lo antiguo ha pasado" (2Co 5,17). Los pecados son realmente borrados y sustituidos por la gracia, por lo que la naturaleza está herida e inclinada al mal, pero no simplemente corrompida. Los justificados permanecen, en este sentido, santificados, a pesar de ser pecadores; pero también es cierto que nos engañamos si decimos que no tenemos pecado (cf. 1Jn 1, 8-10; Jn 1, 28). "Fallamos en muchas cosas", dice Santiago 3, 2, a lo que Pablo añade: "El bien que quiero hacer no lo hago, y el mal que no quiero, lo hago" $(\mathrm{Rm} 7,19)$. De ahí la continua oración pidiendo perdón por nuestros pecados y la súplica de ayuda para vivir en Cristo en plenitud. Por eso, luteranos y católicos, a pesar de nuestras diferencias sobre la doctrina de la justificación y la santificación, podemos comprender juntos en este sentido al cristiano como simul iustus et peccator, como que somos pecadores, pero no estamos ni corrompidos ni empecatados de modo irremisible (cf. nn. 28-30; anexo n. 2) ${ }^{15}$.

15 Sin embargo, no se acaba de ver cómo compatibilizar la explicación luterana del simul justus et peccator del n. 29 con la doctrina católica del anexo, n. 30. En esta, el bautismo borra todo pecado y queda tan solo la concupiscencia, mientras que para los luteranos esta ya sería verdadero pecado. Asimismo, la expresión "oposición a Dios" [Gottwidrigkeit], usada en los nn. 28-30, resulta ambigua, pues católicos y luteranos la utilizan de manera diversa. Por tanto, el anexo pregunta si la doctrina del simul iustus et peccator así presentada no sigue cayendo bajo las condenas de Trento, por lo que requeriría ulteriores profundizaciones. Respecto a las nociones de concupiscencia y pecado, dice allí: "El concepto de 'concupiscencia' [Konkupiszenz] es usado por católicos y luteranos con sentidos diferentes. En los escritos confesionales luteranos la concupiscencia es entendida como el apetito [Begehren] del hombre, mediante el cual el hombre se busca a sí mismo, y que a la luz de la Ley -espiritualmente entendida- es visto como pecado. En la comprensión católica, la concupiscencia es una inclinación que permanece en los hombres aún después del bautismo, que proviene del pecado y conduce a él. A pesar de las diferencias aquí incluidas, desde la perspectiva luterana se puede reconocer que el deseo [Begierde] puede convertirse en la puerta de entrada [Einfallstor] por la que ataca el pecado. Debido al poder del pecado, todo hombre lleva en sí la tendencia de oponerse a Dios, la cual, de acuerdo con las concepciones católica y luterana, "no corresponde al designio inicial de Dios sobre el hombre" (n. 30). El pecado tiene un carácter personal y lleva en cuanto tal a la separación de Dios: es el deseo egoísta del hombre viejo y la falta de confianza y de amor a Dios" (anexo, 
De igual manera la antinomia luterana entre Ley y Evangelio es abordada también por nuestro documento (nn. 31-33). Según los protestantes, la afirmación del segundo no implica la negación de los mandamientos, pues estos expresan la voluntad de Dios. La distinción entre Ley y Evangelio significa que el pecador, "mediante la fe en el Evangelio, ha de volverse sin reservas a la misericordia de Dios en Cristo, que es la única que le justifica" (n. 32). A su vez, "cuando los católicos acentúan que el justo está obligado a observar los mandamientos de Dios, no por ello niegan que -mediante Jesucristo- Dios ha prometido misericordiosamente a sus hijos la gracia de la vida eterna" (n. 33). Sobre la conocida quastio disputata sobre si el cristiano puede tener la certeza de su propia salvación, la DCDJ afirma que el creyente puede confiar en la promesa divina (cf. nn. 34-36). "Los católicos pueden compartir la intención de los reformadores de fundamentar la fe en la realidad objetiva de la promesa de Cristo, prescindiendo de la propia experiencia y confiando solo en la palabra de perdón de Cristo (cf. Mt 16, 19; 18, 18)" (n. 36).

En fin y en lo que se refiere a la debatida cuestión de las buenas obras del justificado, sostiene el texto consensuado que los católicos no niegan con la palabra "mérito" que la justificación sea un don gratuito; y los luteranos reconocen un crecimiento en la gracia y en la fe por parte del justificado (cf. nn. 37-39). Por lo tanto, "juntos confesamos que las buenas obras —una vida cristiana en fe, esperanza y amor-, siguen a la justificación y son frutos de ella" (n. 37). Las buenas obras son siempre fruto de la gracia, pues las precede; pero, sin disminuir el protagonismo y prioridad de la iniciativa divina, la doctrina católica sostiene que es también fruto del hombre justificado y transformado interiormente por la gracia divina por medio de la inhabitación trinitaria. La vida cristiana es toda ella gracia, pero también requiere una respuesta libre a esta, que se expresa en las buenas obras practicadas por la caridad, matiza de nuevo la Declaración apelando al mencionado principio paulino (cf. Ga 5, 6; anexo 2, D). El acuerdo de la justificación tiene por ello la posibilidad de abrir el camino en las relaciones católico-luteranas, para abordar otras cuestiones que, sin esta premisa, estarían en el aire. Es el mismo documento el que lo subraya en el n. 43 , ya casi al final:

Quedan pendientes cuestiones de importancia -concluye- que requieren

2, B). Una buena exposición aparece en W. KASPER, "La Dichiarazione congiunta sulla dottrina della giustificazione", 9 . 
ulterior aclaración, entre ellas: la relación entre la palabra de Dios y la doctrina de la Iglesia, la eclesiología, la autoridad de la Iglesia, el ministerio, los sacramentos y la relación entre justificación y ética social. Estamos convencidos de que el consenso que hemos alcanzado sienta sólidas bases para esta ulterior aclaración.

\section{Desarrollos y PRofundizaciones}

En esta misma línea, seis años después, Benedicto XVI pronunciaba -en el país donde nació la Reforma- unas palabras que nos pueden servir de orientación para un ulterior estudio teológico que de verdad suscite el diálogo ecuménico: "Pienso que de este modo el problema eclesiológico, así como el del ministerio, no se afrontan de modo correcto. La cuestión verdadera es la presencia de la Palabra en el mundo". Recordaba allí cómo por ejemplo la Iglesia primitiva, en el siglo II, había tomado tres decisiones: en primer lugar, es necesario establecer el canon bíblico, "subrayando así la soberanía de la Palabra y explicando que no solo el antiguo testamento es hai grafai", sino que, juntamente con él, el nuevo testamento constituye una sola Escritura y, de este modo, "es para nosotros nuestro verdadero soberano". Pero, al mismo tiempo, recordaba el papa alemán que la Iglesia formuló la sucesión apostólica y el ministerio episcopal, consciente de que "la Palabra y el testigo van juntos" (es decir, que la Palabra está viva y presente solo gracias al testigo y, por decirlo así, recibe de él su interpretación), y que recíprocamente el testigo solo es tal si da testimonio de la Palabra. Y, por último, "la Iglesia añadió un tercer elemento: la regula fidei, como clave de interpretación”. La mutua complementariedad entre Escritura e Iglesia, si bien esta se encuentra subordinada a aquella, constituye un punto de partida hermenéutico. "Pienso que esta compenetración mutua es objeto de divergencias entre nosotros, aunque nos unen cosas fundamentales"16.

16 Discurso en el encuentro ecuménico, Arzobispado de Colonia, 19 de agosto de 2005: AAS XCVII (2005/9) 911-915. Sobre el problema de la interpretación de la Escritura en ambas confesiones cristianas, puede verse: S. Grosse, «Sola Scriptura. Un principio de la Reforma en reflexión ecuménica», Scripta Theologica 49 (2017) 151-170, y V. BALAGUer, "La Sagrada Escritura "una cum sancta Traditione" ante el reto de la sola Scriptura», Scripta Theologica 49 (2017) 171-192. Por tanto, concluía el recién elegido papa, "cuando hablamos de eclesiología y de ministerio, deberíamos hablar preferentemente de este entrelazamiento entre Palabra, testigo y regla de fe, y considerarlo como cuestión eclesiológica". Por eso, también hemos de estudiar la "cuestión de la palabra de Dios, de su soberanía y de su humildad", puesto que Dios confía su Palabra a los testigos y les encomienda su interpretación. Pero esta "debe regirse siempre por la regula fidei y por la seriedad de la Palabra".

"Perdonadme que haya expresado aquí -concluía sin una pose demasiado magisterial- una opi- 
El diálogo debía pues continuar en torno a estas materias propuestas y especialmente sobre la cuestión de la interpretación de la Escritura. En este sentido, además del documento común Del conflicto a la comunión (2013) ${ }^{17}$, la Declaración en camino sobre Iglesia, ministerio y eucaristía de $2015^{18}$, suscrito por la Conferencia episcopal estadounidense y la Iglesia evangélico-luterana de América (y que recoge los frutos alcanzados durante cincuenta años en diálogos locales y oficiales), supone un hito para preparar el quinto centenario de la ruptura de Lutero con Roma. En el prólogo de esta Declaración, el texto nos recuerda que "es bueno volver a recorrer el camino que hemos hecho juntos y mencionar los puntos de convergencia que juntos hemos alcanzado", a la vez que "enumera los temas que tradicionalmente dividen a luteranos y católicos en lo que se refiere a la Iglesia, el ministerio y Eucaristía”. Así como en 1999 fue firmada una Declaración Conjunta sobre la Doctrina de la Justificación, urge pues ahora un documento común sobre estos tres grandes temas -eucaristía, ministerio, eclesiología- de tanta relevancia para el ecumenismo y la vida de la Iglesia. En esta misma línea se trabajó en el ámbito escandinavo, especialmente en Suecia y en Finlandia ${ }^{19}$.

nión personal, pero me parecía oportuno hacerlo". También recordaba asimismo "las grandes cuestiones éticas que plantea nuestro tiempo", pues estas constituyen "una prioridad urgente en el diálogo ecuménico". En efecto, en este campo, los hombres y mujeres de hoy que buscan a Dios, "esperan con razón una respuesta común de los cristianos, que, gracias a Dios, en muchos casos casi se ha encontrado" (cf. ibid.).

En 2011, el Papa alemán volvía a abordar la cuestión luterana en la visita al convento de los agustinos donde Martín Lutero permaneció desde 1505 a 1511. Allí Benedicto XVI recordó que "lo que le quitaba la paz [a Lutero] era la cuestión de Dios, que fue la pasión profunda y el centro de su vida y de su camino". Tras haber hecho una referencia al profundo interés del reformador por el misterio del mal, del pecado y de la necesidad de un Dios misericordioso, el Papa alemán se refirió al núcleo del problema: "No, el mal no es una nimiedad. No sería tan poderoso si nosotros pusiéramos a Dios realmente en el centro de nuestra vida", por lo que eran requeridos "la vivencia y el testimonio de la verdad de la fe" (Discurso en el encuentro ecuménico con luteranos, Erfurt, 23 de septiembre de 2011).

17 Del conflicto a la comunión. Conmemoración conjunta luterano-católico romana de la Reforma en el 2017. Informe de la Comisión Luterano-Católico Romana sobre la Unidad (Sal Terrae, Santander 2013).

18 Bishops Comittee for Ecumenical and Interreligious Affairs - Evangelical Lutheran Church in America, Declaration on the Way: Church, Ministry and Eucharist, United States Conference of Catholic Bishops, Washington D.C. 2015: disponible en: http://www.usccb. org/beliefs-and-teachings/ecumenical-and-interreligious/ecumenical/lutheran/upload/Declaration_on_the_Way-for-Website.pdf [consulta 9.1.2016].

19 Lutheran-Catholic Dialogue Commission for Sweden and Finland, Justification in the life of the Church, Uppsala, Stockholm and Helsinki 2010; Lutheran-Catholic Dialogue Commission for Finland, Communion in Growth. Declaration on Church, Eucharist, and Ministry (Grano, Helsinki 2017). 
También en un encuentro el 18 de diciembre de 2014 en la Iglesia evangélica luterana alemana de Roma, el papa Francisco recordaba que, a pesar de las diferencias teológicas que persisten en diversas cuestiones de fe, la colaboración y la convivencia fraterna caracterizan la vida de las Iglesias y comunidades eclesiales, comprometidas en un camino ecuménico común, y concretadas en textos conjuntos como la Declaración Conjunta sobre la Doctrina de la Justificación, firmada oficialmente hacía más de quince años en Augsburgo: "son -dijo el obispo de Roma- piedras angulares, que permiten seguir con confianza el camino emprendido". Y aunque el objetivo común de la plena y visible unidad a veces parezca alejarse a causa de diferentes interpretaciones sobre lo que es la Iglesia y su unidad, es necesario no ceder a la resignación sino concentrarse en el próximo paso posible que debemos dar juntos.

No olvidemos -subrayó el obispo de Roma- que recorremos juntos el camino de la amistad, del respeto mutuo y de la investigación teológica; un camino que nos hace mirar con esperanza al futuro. Por eso el pasado 21 de noviembre las campanas de todas las catedrales de Alemania tocaron para invitar a todos los hermanos cristianos a un servicio litúrgico común por el quincuagésimo aniversario de la promulgación del Decreto Unitatis redintegratio del Vaticano $\mathrm{II}^{20}$.

Con motivo del quinto centenario de aquel 31 de octubre de 1517, algunas comunidades luteranas pidieron la "hospitalidad eucarística" con

20 En esta misma línea, añadía el papa Francisco el 31 de octubre de 2016, en la histórica visita a la catedral de Lund, en Suecia, con motivo de los quinientos años de la Reforma inaugurada por Lutero: "La experiencia espiritual de Martín Lutero nos interpela y nos recuerda que no podemos hacer nada sin Dios. «¿Cómo puedo tener un Dios misericordioso?». Esta es la pregunta que perseguía constantemente a Lutero. En efecto, la cuestión de la justa relación con Dios es la cuestión decisiva de la vida. Como se sabe, Lutero encontró a ese Dios misericordioso en la Buena Nueva de Jesucristo encarnado, muerto y resucitado. Con el concepto de «solo por la gracia divina", se nos recuerda que Dios tiene siempre la iniciativa y que precede cualquier respuesta humana, al mismo tiempo que busca suscitar esa respuesta. «La doctrina de la justificación, por tanto, expresa la esencia de la existencia humana delante de Dios».

"Jesús intercede por nosotros como mediador ante el Padre, y le pide por la unidad de sus discípulos "para que el mundo crea» (Jn 17, 21). Esto es lo que nos conforta, y nos mueve a unirnos a Jesús para pedirlo con insistencia: «Danos el don de la unidad para que el mundo crea en el poder de tu misericordia». Este es el testimonio que el mundo está esperando de nosotros. «Los cristianos seremos testimonio creíble de la misericordia en la medida en que el perdón, la renovación y la reconciliación sean una experiencia cotidiana entre nosotros. Juntos podemos anunciar y manifestar de manera concreta y con alegría la misericordia de Dios, defendiendo y sirviendo la dignidad de cada persona. Sin este servicio al mundo y en el mundo, la fe cristiana es incompleta" (Homilía en el encuentro ecuménico, Catedral de Lund, 31 de octubre de 2016: AAS CVIII (2016/11) 1253). 
la Iglesia católica, es decir, poder recibir la comunión eucarística en una celebración católica. Quedaba sin embargo todavía un largo camino por recorrer, como hemos estado viendo. Junto con el luterano Harding Meyer (n. 1928), el cardenal suizo Kurt Koch (n. 1950), actual presidente del Consejo para la unidad de los cristianos, animó a dar "nuevos pasos hacia la unidad", pues una "nueva Declaración común sobre la Iglesia, la Eucaristía y el ministerio" constituía "un paso decisivo en el camino hacia la comunión plena de las Iglesias". Mientras el diálogo oficial católico-luterano sobre estos tres temas ha dado abundantes frutos en los años posteriores al Vaticano II, los teólogos de ambas confesiones profundizan en las respectivas doctrinas sin llegar a un pleno acuerdo en todos y cada uno de los puntos.

Muchos miembros de nuestras comunidades anhelan recibir la Eucaristía en una mesa -recordaba el papa Francisco ese otońo en Lund-, como expresión concreta de la unidad plena. Sentimos el dolor de los que comparten su vida entera, pero no pueden compartir la presencia redentora de Dios en la mesa de la eucaristía. Reconocemos nuestra conjunta responsabilidad pastoral para responder al hambre y sed espiritual de nuestro pueblo con el fin de ser uno en Cristo. Anhelamos que sea sanada esta herida en el cuerpo de Cristo. Este es el propósito de nuestros esfuerzos ecuménicos, que deseamos que progresen, también con la renovación de nuestro compromiso en el diálogo teológico ${ }^{21}$.

Supone, por tanto, un "ya, pero todavía no" que mueve al trabajo, la oración, la conversión y el diálogo teológico que deben continuar. En efecto, para algunos cristianos protestantes, el concepto de mediación sigue resultando algo problemático: afirman, por ejemplo, que no todos creen que deben reconocer al obispo que representa a Cristo, o que no es necesario un profundo consenso en estos puntos doctrinales para llegar a la mutua comunión eucarística. La Iglesia católica insiste -junto con las Iglesias ortodoxas- en la necesidad de la previa comunión en la fe para poder acceder a la comunión eucarística. Además, los protestantes deben considerar las importantes diferencias con la noción de sacramento, tan importante en la teología posconciliar católica. Los sacramentos fueron considerados por los Padres de la Iglesia huellas de la encarnación del Verbo, memorial de la pascua del Señor y una continuación de la acción salvífica de Cristo: lejos de

21 Homilia en el encuentro ecuménico, Catedral de Lund, 31 de octubre de 2016: AAS CVIII $(2016 / 11) 1261$. 
este "pensar sacramental", todavía algunos teólogos luteranos afirman que no llegará la modernidad hasta que el ecumenismo deje de hablar de categorías tales como Iglesia, ministerio y sacramento. Siguen existiendo pues aquí grandes diferencias con la concepción católica y ortodoxa ${ }^{22}$.

\section{Perspectivas de futuro}

La profundización y las explicaciones han continuado su curso y nos han permitido profundizar más y más en el sentido de este acuerdo. En una interesante publicación de $2016^{23}$, eran planteadas algunas preguntas sobre el texto comentado. La primera parte presentaba el problema, seguido de un capítulo sobre la historia del desarrollo de la Declaración conjunta ${ }^{24}$. El siguiente capítulo involucraba a los principales críticos del acuerdo; quedaba así claro que los replanteamientos se dividen en dos tipos diferentes, relacionados con el contenido de la fe tal como se presenta en la Declaración, y aquellos otros que presentan la posibilidad de un "consenso diferenciado" (a pesar de que no se usa explícitamente este término), es decir, "un consenso en el que las partes llegan a presupuestos comunes que son aplicados de modo diferente según el propio lenguaje" 25 . La segunda de estas categorías es sin embargo mucho más importante. Antes de examinar las cuestiones particulares de contenido resulta necesario preguntar si un consenso diferenciado es posible y, si es así, qué posibilidades de éxito podría tener. Esta segunda parte representa una especie de "acercamiento" a la cuestión más amplia del consenso en el diálogo ecuménico ${ }^{26}$. En esta línea, el capítulo cuarto de este "mapa de la DCDJ" ofrece una serie de consideraciones ecuménicas de lo que constituye tal consenso ${ }^{27}$, mientras el capítulo quinto lo reseńa directamente: será allí aclarado que, si bien este ha sido reconocido por los participantes del diálogo, todavía no existe una explicación adecuada de por qué podrían ser en verdad posibles, pues en ningún caso constituirían un acto de relativismo ${ }^{28}$.

22 Referido a un caso particular y sin poder generalizarlo a toda su teología, puede verse: I.U. DaLfERTH, Auf den Weg der Ökumene. Die Gemeinschaft evangelischer und anglicanischer Kirchen nach der Meißener Erklärung (Evangelische Verlagsanstalt, Leipzig 2002) 257.

23 J.K. Rinderknecht, Mapping the Differentiated Consensus of the Joint Declaration (Palgrave Macmillan, London 2016).

24 Ibíd. 9-11.

25 Ibíd. 4.

26 Ibíd. 11-39.

27 Ibíd. 55-77.

28 Ibíd. 79-99. El sexto capítulo, por su parte, nos ofrece el consenso diferenciado a la luz del 
Tras un acercamiento lingüístico pasaríamos a los apartados más propiamente teológicos del presente estudio. Los capítulos 8 y 9 abordan la cuestión desde la teología católica, específicamente desde una consideración de la concupiscencia en los bautizados. Trento reconoce que esta permanece en los cristianos, la cual no resulta indiferente incluso sin ser pecado: establece así una doble visión del cristiano como alguien salvado por la incorporación a Cristo por el Espíritu, pero sin presentar la plenitud de esa incorporación a la gracia y luchando todavía contra tal inclinación al pecado. Este constituye siempre una separación de Dios. Así pues, el pecador justificado participa ya en lo que ha de convertirse, si bien no lo es del todo ${ }^{29}$. Los capítulos 10 y 11 vuelven a la teología luterana y sigue el mismo procedimiento, al plantear el pecado como opuesto a la ley de Dios. Aquí la pregunta planteada es el aforismo luterano simul iustus et peccator, tal como había señalado el citado comentario católico; sigue siendo este por tanto el punctum dolens de la interpretación de la doctrina de la justificación, junto con la mencionada distancia del concepto de santificación, a pesar del mencionado consenso ${ }^{30}$. La simultánea afirmación de naturaleza, libertad y gracia resultan ser así las claves interpretativas del común texto ecuménico ${ }^{31}$. Rinderknecht insiste en que la DCDJ supone que el consenso diferenciado consistente en mantener los distintos acentos sin negar la posición contraria, guiados siempre por la mencionada "hermenéutica de la confianza": sería como hablar distintos

lenguaje y del conocimiento humanos. Considera de esta manera los puntos de vista de los lingüistas cognitivos contemporáneos respecto a la estructura del lenguaje, especialmente en el papel que desempeña la combinación cognitiva en la construcción del significado. Aquí, la razón nos ayuda a establecer diferencias. Para que un consenso diferenciado sea posible, resulta necesario mediar entre las diferentes tradiciones del discurso, como ocurre cuando dos tradiciones cristianas del discurso teológico buscan acordar cuestiones que históricamente las han dividido (cf. ibid., 101-145).

29 Ibíd. 147-193.

30 Un contraargumento lo encontramos en WA 56, 442.

31 J.K. Rinderknecht, Mapping the Differentiated Consensus of the Joint Declaration, 195-243. En efecto, afirma más adelante: "Los católicos continuarán insistiendo en que la concupiscencia no es propiamente pecado, si no hay consentimiento, en el sentido de que no nos separa propiamente de Dios. [...] Los luteranos están de acuerdo en que, mientras la concupiscencia está bajo el dominio de Cristo, no causa dańo al cristiano, pero lo denomina pecado precisamente porque va en contra de la ley de Dios y no estará presente en su reino" (257). Por eso detecta entre ambas confesiones cristianas "diferencias de lenguaje" (258), a la vez que vuelve la insistencia católica en la vida sacramental, "enraizada en la Iglesia como cuerpo de Cristo" (259). Respecto a la mencionada vexata quaestio, afirma: "el simul no puede ser entendido como que el cristiano es pecador en el sentido de que está separado de Dios, o de que el pecado está descontrolado dentro de él" (260). 
dialectos sobre la base de una misma lengua. "Los modos de actuar luterano y católico parecen estar en contradicción el uno con el otro, pero resulta ser una aparente contradicción procedente de unas determinadas denominaciones cognitivas (cognitive blends) del concepto de pecado que cada tradición emplea y de la clase de marco que cada denominación ofrece"32. Sin renunciar a los matices y críticas propios, puede llegarse a un consenso sobre lo esencial, si bien los conceptos de naturaleza y pecado han de corregirse y matizarse -ampliarse- mutuamente. But Christian unity -concluye-will always be a unity in the truth ${ }^{33}$.

El mismo papa emérito Benedicto XVI terció entonces en el debate ${ }^{34}$. Tras publicar una entrevista con el papa emérito Benedicto XVI, el teólogo francés Jacques Servais la comentaba en las páginas siguientes ${ }^{35}$. El contexto es el cumplimiento de los 500 ańos desde el inicio de la reforma protestante y de la celebración del Jubileo de la misericordia convocado por el papa Francisco (interesante coincidencia), y tras presentar la fides ex auditu como el fruto de un encuentro que crea conocimiento, el papa emérito insistía en el carácter donado de esta realidad sobrenatural que exige ser vivida. A la vez, traía a la memoria el carácter social y comunitario de este don que es recibido en el "nosotros" de la Iglesia. En efecto, la Esposa -menciona en términos queridos a la Reforma- constituye una realidad igualmente recibida que nos remite necesariamente al Esposo, y es aquí donde recuerda precisamente la necesaria dimensión litúrgico-sacramental originaria para acceder a la gracia bautismal, con lo que estamos poniendo las bases para una consideración sacramental de la realidad eclesial ${ }^{36}$. Allí cita a su sucesor en el solio pontificio, referido al énfasis establecido sobre el núcleo del mensaje cristiano:

Solo allí donde está la misericordia acaba la crueldad, terminan el mal y la violencia. El papa Francisco se encuentra en perfecta sintonía con esta idea. Su experiencia pastoral insiste precisamente en el hecho de que él nos habla continuamente de la misericordia de Dios ${ }^{37}$.

32 Ibid. 263.

33 Ibid. 8.

34 J. SERvaIs, Comprendre de maniere nouvelle. Notes en marge de l'interview du pape émérite Benoît XVI (Parole et Silence, Paris 2017).

35 Ibíd. 9-35, 39-134.

36 Ibíd. 12-15.

37 Ibíd. 18. En lo que se refiere a la doctrina de la salvación vista ahora bajo el prisma de la misericordia reclamada por Lutero, Servais apela al desarrollo orgánico del dogma, vaticinado 
Así, continuaba el teólogo-papa emérito, la doctrina luterana sobre la justificación por la sola fe ha de ser tamizada por el misterio de la misericordia divina. Ambos misterios están recíprocamente implicados. Sin embargo, "es necesario superar la tentación de oponer la misericordia de Dios a su justicia. La misericordia no sustituye a la justicia, sino que la desarrolla"38, matizaba Servais en sintonía tanto con Benedicto XVI como con el papa Francisco. La justificación del creyente vendrá siempre como acto de misericordia por parte del Padre y, sin caer en soluciones laxistas ni rigoristas, resulta igualmente imprescindible la verdad cristiana en el ámbito de la salvación $^{39}$. Por eso las religiones no cristianas presentan un papel precursor y provisional respecto a la plenitud de la misericordia divina que nos ha sido revelada en Jesucristo. Esto confiere al mensaje cristiano una dimensión universal y misionera, tal como destacó Henri de Lubac en su obra Catolicismo. Aspectos sociales del dogma $(1938)^{40}$. Por eso la Iglesia es tan necesaria como Cristo para la justificación del pecador y la salvación de toda la humanidad; pero esta ha de tener también -recuerda el teólogo jesuita- presente la dimensión marial de la Iglesia, recuerda siguiendo a Ratzinger-Bergoglio ${ }^{41}$. El papa emérito rememoró también de modo continuo en esta entrevista la esencial unidad entre amor y verdad, pues cuando "la misericordia y la fidelidad se encuentran, la justicia y la paz se besan” (Sal 85, 11) ${ }^{42}$.

La Confederación luterana mundial publicaba en 2018 una guía de

por Newman y mencionado por Benedicto XVI (cf. 56ss.). En este sentido, correspondería a toda la Iglesia el descubrir las virtualidades ocultas y latentes presentadas en esta concepción de la misericordia divina. No se trata por tanto de un nuevo paradigma, sino de una enseñanza que en continuidad y correlación con todas las del magisterio previo que, bajo la inspiración del Espíritu, ha ido recordando a lo largo de los siglos. Al mismo tiempo, el teólogo jesuita es consciente de la novedad del mensaje de la santa polaca Faustina Kowalska (1905-1938), lo cual ofrece a su vez numerosas posibilidades interpretativas. De esta forma, la revelación es asimilada a la "semilla de mostaza" (Mt 13,32), que ofrece infinitas virtualidades de desarrollo en el futuro, siempre que sea tenida en cuenta la condición eclesial de esta verdad entregada por Cristo a su Iglesia: esta "no debe dejar de examinar el inagotable misterio de la verdad que él le ha confiado, y de profundizar en aspectos hasta ahora ignorados, contribuyendo de este modo a una forma de auténtico desarrollo dogmático" (63).

Cf. ibíd. 75; cf. 95-97.

39 Ibíd. 107-108.

40 Ibíd. 119-120; la obra mencionada es Catholicisme. Les aspects sociaux du dogme (Édition du Cerf, Paris 1938).

41 Ibid. 119-120.

42 Cfr. ibíd. 134. 
"tareas ecuménicas", con motivo de los setenta años de su fundación ${ }^{43}$. Además de reivindicar un empleo adecuado de la terminología, apelaba al ejercicio de un ecumenismo pastoral y espiritual, a la vez de fomentar el diálogo teológico ${ }^{44}$. Proponía allí una vez más el modelo de la "diversidad reconciliada”, ya auspiciado por Oscar Cullmann (1902-1999), mientras nuestro documento es considerado como "el más importante resultado ecuménico".

La Declaración conjunta establece que luteranos y católicos comparten una comprensión básica sobre la doctrina de la justificación y que no pueden ser aplicadas las condenas formuladas en el siglo Xvi. Luteranos y católicos han continuado este espíritu de reconciliación establecido por la Declaración Conjunta sobre la Doctrina de la Justificación ${ }^{45}$.

Resulta igualmente evocado el encuentro en la catedral de Lund entre el papa Francisco y el presidente general de la Confederación luterana mundial. A continuación son mencionados los diálogos bilaterales de los luteranos con otras confesiones cristianas: ortodoxos, anglicanos, metodistas, reformados, menonitas y pentecostales ${ }^{46}$.

\section{Consideraciones CONCLUSIVAS}

En cualquier caso, la adhesión a la DCDJ no solo de luteranos y católicos, sino también del Consejo metodista mundial en 2006, de la Alianza reformada mundial y de la Comunión anglicana en 2017 indica que esta Declaración constituye una piedra miliar, un punto de partida en el que debemos proseguir el camino. En esta misma línea, habría que ampliar este acuerdo teológico también a otras denominaciones protestantes, a la vez que extender los buenos resultados obtenidos por el método del "consenso diferenciado": abrir la propia perspectiva con la otra, a la vez que no se reniega de ninguno de los principios complementarios, evitando de esta forma toda controversia o postura dialéctica. De esta forma, resulta indispensable la profundización en los textos bíblicos sobre los distintos temas teológicos, para llegar a cualquier acuerdo teológico. La cuestión hermenéutica cobra

43 The Lutheran World Federation's Commitments on the Ecumenical Way to Ecclesial Communion (Departament for Theology and Public Witness, Geneva 2018).

44 Cf. ibíd. 25-26.

45 Ibíd. 12.

46 Ibíd. 12-14 
así un protagonismo clave, tal como hemos estado viendo. Por otra parte, no hemos de olvidar que los viejos temas polémicos -como las buenas obras, la concupiscencia o el simul iustus et peccator- requieren a su vez una reinterpretación, que permiten tal vez entender que la otra propuesta es más complementaria que contraria. No consiste tan solo en un cambio de actitud, sino comprender distintos temas debatidos. La afirmación de un consenso no monolítico surgido de la "hermenéutica de la confianza" (en pocas palabras, de un "consenso diferenciado" en una "diversidad reconciliada") sobre verdades fundamentales acerca de la doctrina de la justificación por la fe abrió un nuevo camino en el diálogo entre ambas Iglesias. Este trecho recorrido debe seguir siendo guiado por el logro histórico obtenido por la DCDJ.

Es por tanto un motivo de acción de gracias a Dios y de ulterior reflexión teológica, y estamos sobre el camino que nos dirige hacia el futuro, aunque todavía necesitamos ahora una Declaración conjunta sobre Eucaristía, ministerio y eclesiología, que puede traer consigo interesantes consecuencias en el ámbito de la vida ecuménica. No hemos de olvidar sin embargo tampoco las cuestiones morales (bioética, doctrina social, medio ambiente) donde no siempre existe un consenso absoluto. Además, para alcanzar posteriores consensos tal vez sería interesante comprender el principio protestante de la sola Scriptura según el moto igualmente luterano Scriptura numquam sola (es decir, de la cuestión hermenéutica). Es el verdadero punto de partida de toda interpretación realizada por la teología protestante. Confiemos por tanto que la acción del Espíritu ilumine estos intentos y podamos acercarnos más y más a la meta propuesta por nuestro Señor: "que todos sean uno" (Jn 17,21). 